\title{
Poor mental health and sexual risk behaviours in Uganda: A cross-sectional population-based study
}

Patric Lundberg ${ }^{1,2^{*}}$, Godfrey Rukundo ${ }^{3}$, Schola Ashaba ${ }^{3}$, Anna Thorson ${ }^{4}$, Peter Allebeck ${ }^{1}$, Per-Olof Östergren ${ }^{2}$, Elizabeth Cantor-Graae ${ }^{2}$

\begin{abstract}
Background: Poor mental health predicts sexual risk behaviours in high-income countries, but little is known about this association in low-income settings in sub-Saharan Africa where HIV is prevalent. This study investigated whether depression, psychological distress and alcohol use are associated with sexual risk behaviours in young Ugandan adults.

Method: Household sampling was performed in two Ugandan districts, with 646 men and women aged 18-30 years recruited. Hopkins Symptoms Checklist-25 was used to assess the presence of depression and psychological distress. Alcohol use was assessed using a question about self-reported heavy-episodic drinking. Information on sexual risk behaviour was obtained concerning number of lifetime sexual partners, ongoing concurrent sexual relationships and condom use.

Results: Depression was associated with a greater number of lifetime partners and with having concurrent partners among women. Psychological distress was associated with a greater number of lifetime partners in both men and women and was marginally associated $(p=0.05)$ with having concurrent partners among women. Psychological distress was associated with inconsistent condom use among men. Alcohol use was associated with a greater number of lifetime partners and with having concurrent partners in both men and women, with particularly strong associations for both outcome measures found among women.

Conclusion: Poor mental health is associated with sexual risk behaviours in a low-income sub-Saharan African setting. HIV preventive interventions should consider including mental health and alcohol use reduction components into their intervention packages, in settings where depression, psychological distress and alcohol use are common.
\end{abstract}

\section{Background}

Is poor mental health associated with sexual risk behaviours in sub-Saharan Africa? This question has not been conclusively answered despite its relevance for HIV prevention [1,2].

Poor mental health is a major cause of disability in low-income countries, with depression constituting the heaviest disease burden [3]. The HIV epidemic may contribute to increased depression rates in countries having high HIV prevalence: HIV may lead to depression both in persons who live with HIV $[4,5]$ and in those who are indirectly affected [6-8]. An association

\footnotetext{
* Correspondence: patric.lundberg@ki.se

'Division of Social Medicine, Department of Public Health Sciences,

Karolinska Institute, Stockholm, Sweden

Full list of author information is available at the end of the article
}

between depression and sexual risk behaviours is thus particularly relevant in low-income countries with high HIV prevalence.

In high-income countries, poor mental health has been closely linked to risky sexual behaviours [9]. For instance, longitudinal studies from the United States suggest that depressive symptoms contribute to sexual risk behaviours (multiple sexual partners, unprotected sex) in the general population, with potential mechanisms including maladaptive coping, low self-efficacy, and self-destructiveness [10-12]. However, the relationship between depressive symptoms and sexual risk behaviours may be non-linear: persons having moderate, but not severe, depressive symptoms may engage in the most sexual risk behaviours [13]. 
However, conclusions derived from findings in highincome countries may not be applicable to low-income settings. Sexual behaviours vary widely between and within countries, and are determined both by context and individual factors [14]. In many sub-Saharan African low-income countries, contextual factors such as poverty/wealth, mobility, and gender inequality heavily influence sexual behaviours [14-18]. In contrast, in highincome countries, personal choice may have a greater influence.

Nevertheless, to our knowledge only three studies have previously investigated the association between poor mental health and sexual risk behaviours in the general population in sub-Saharan African countries: In South Africa, depressive symptoms predicted transactional sex and intimate partner physical and sexual violence in women, and inconsistent condom use in men [19], while cross-sectional associations with sexual risk behaviours have also been found $[19,20]$. In Botswana, cross-sectional associations were found between depressive symptoms and having multiple partners among women, and with paying for sex among men [21]. In addition, South Africa and Botswana are both middleincome countries, and to our knowledge, no populationbased study has investigated the association between poor mental health and sexual risk behaviours in a lowincome sub-Saharan African setting.

Thus, we investigated the association of (1) depression, (2) psychological distress, i.e. depressive and anxiety symptoms, and (3) alcohol use, with sexual risk behaviours in young Ugandans in the general population. Uganda is a low-income country with a generalised HIV epidemic (prevalence in 2005: 6.4\% [22]). Moreover, population-based surveys suggest that mental health problems are very common in the country (depression prevalence range: 10-50\%) [23-26], and mental health services are sparse with 0.8 psychiatrists per one million population [27].

\section{Method}

\section{Participants}

The study took place in Kampala (mainly Baganda ethnic group) and Mbarara district (mainly Banyankole ethnic group). The Baganda and Banyankole are culturally and linguistically related.

We performed a cross-sectional population-based study in nine purposively selected study areas representing varying degrees of urbanicity in Uganda: 3 divisions in Kampala city (urban), 3 divisions in Mbarara town (semi-urban), and 3 sub-counties in Mbarara district (rural). Persons aged 18-30 years, residing in these areas and not reporting or displaying overt signs of severe mental or physical illness, and not under the influence of alcohol or drugs at the time of contact, were eligible.
This age group was selected because it was deemed to represent the segment of the adult population being most sexually active.

In each study area, seven villages (in rural areas) or neighbourhoods (in semi-urban/urban areas) were purposively selected, in order to reflect the range of levels of economic development of villages/neighbourhoods in the study area. From a central location in each selected village/neighbourhood, a walk was performed in a random direction, towards the end of the village/neighbourhood. The random direction was obtained spinning a pen and observing in what direction the pen pointed after the spinning had stopped. Every third household encountered during the walk was visited, until ten interviews had been conducted, thus yielding an approximate sample size of $9 \times 7 \times 10=630$ participants in total. All eligible persons at home were interviewed. If no eligible person was at home the next household was visited, and then, every third household. Follow-up visits were not performed. In four of the 21 selected neighbourhoods in Kampala, household sampling proved not to be feasible using our random walk procedure, given a low density of accessible households and a predominance of shops and businesses in the neighbourhood. In these neighbourhoods a pragmatic approach was adopted: Instead of households, shops and businesses were sampled using the same systematic sampling strategy as that used for households, with participants systematically recruited inside the selected establishments.

Among the persons who were approached and invited for participation, refusals were rare (estimated at $<5 \%$ ). Data was collected between September 2004 and June 2005 by seven Ugandan field workers (university students). Initial training focussed on interviewing techniques and ethical considerations specific to interviews about mental problems and sexual behaviours. Interviewers and respondents were not sex-matched. Continuous supervision was provided throughout the field-work by two of the authors (G.R. and S.A.). Study languages were English, Luganda and Runyankole, depending on the proficiency of the respondent. Informed consent was sought and the risks, benefits and right to decline or withdraw were carefully explained. Although potential participants were sometimes approached in the vicinity of other persons, after informed consent had been obtained, the research assistant and the participant withdrew to a more secluded location where privacy was ensured.

All study procedures were approved by the Institutional Ethical Review Committee of Mbarara University.

\section{Measures}

Socio-demographic background factors were: age (18-24 yrs vs. 25-30 yrs), level of education (up to primary 
school vs. more than primary school), relationship status (single/widowed/separated vs. married/cohabiting), and place of residence (urban vs. semi-urban/rural with urban referring to Kampala district).

Depression was assessed using the depression sub-section of the Hopkins Symptoms Checklist (HSCL-25) [28]. This instrument was developed for cross-cultural use and consists of 25 questions assessing symptoms of anxiety (10 items) and depression (15 items) during the past week, with the response to each item graded from $1=$ "not at all" to $4=$ "extremely". The depression subsection of the questionnaire (15 items) has been validated among the Baganda as a screening tool for probable depression, with a cut-off point established based on comparison with structured clinical interviews $[26,29]$. Thus, we categorized participants having a depression sub-scale total score of 31 or above as having probable depression [26], in order to be able to assess the association of clinical depression with sexual risk behaviours. The Chronbach's alpha for the depression sub-scale was 0.84 , i.e. similar to that previously reported in Uganda [26].

Psychological distress was assessed by calculating a total score for the entire HSCL-25 instrument including both depression and anxiety items [28] as has been done previously [30,31]. Depression and psychological distress only partly overlap. Thus, many persons in the general population have psychological distress but do not fulfil diagnostic criteria for clinical depression. Nevertheless, such persons might potentially have increased sexual risk behaviours. Therefore, we used the HSCL-25 as a continuous measure of psychological distress and investigated whether this measure was associated with sexual risk behaviours. The continuous psychological distress variable was categorised into gender-specific quartiles instead of using e.g. a dichotomous measure, in order to capture sub-clinical psychological distress, and given that a non-linear relationship between psychological distress and sexual risk behaviour was deemed possible [13]. Gender-specific quartiles were used in order to maximise statistical power for within-gender analyses of the association between psychological distress and sexual behaviours. The $1^{\text {st }}$ quartile (i.e. least psychological distress) was used as the reference category to which the other HSCL-25 quartiles were compared. The Chronbach's alpha for the entire instrument was 0.92 , indicating excellent internal consistency, and suggesting that all HSCL-25 items could indeed be used to measure a common underlying construct.

Alcohol use referred to heavy episodic drinking, a behaviour associated with sexual risk taking $[21,32,33]$, and was operationalised as the number of times 'drunk on alcohol' per week ( 0 vs. 1 or more). Self-reports of heavy episodic drinking have previously been used in sub-Saharan African contexts [34] and may provide a viable alternative in settings where estimating the number of 'standard drinks' is difficult: In rural Uganda, a significant proportion of the alcohol consumed is locally produced, has variable alcohol content and is consumed from plastic bags, cups or a common pot.

Sexual behaviours were assessed using three measures:

(1) 'Number of lifetime sexual partners'

Sexual partner was defined as a person with whom one has ever had sexual intercourse. The number of lifetime sexual partners was categorized as $0-3$ vs. 4 or above, approximately corresponding to the $75^{\text {th }}$ percentile in the current sample.

(2) 'Number of current sexual partners'

Current sexual partner was defined as a partner with whom one currently has sexual intercourse regularly. The number of current sexual partners was categorized as $0-1$ vs. 2 or more. This measure thus targeted ongoing regular sexual relationships as has been done previously [35], in order to estimate the point prevalence of concurrency [36]. Two or more current sexual partners are hereafter referred to as concurrent sexual partners.

(3) 'Frequency of condom use when having sex'

This question assessed the conditional likelihood that the person uses a condom in case he or she has sexual intercourse, and therefore used a relative measure of condom use (always, sometimes, never) and did not have a specific reference time period. Conceptualizing condom use as a habit, and using relative instead of count measures may increase sensitivity when investigating the psychological correlates of unprotected sex [37]. Condom use was categorised as always (consistent) vs. sometimes/never (inconsistent) condom use.

The study instrument was translated from English into Runyankole and Luganda and independently back-translated. The two versions were compared and necessary adjustments made (P.L., G.R., S.A. and translators). Care was taken in order not to introduce culturally alien or offensive notions or expressions, while ensuring that the intended construct was indeed being measured. The questions about sexual behaviours were asked at the end of the interview for increased acceptability. After backtranslation and modification, the questionnaire was pretested on persons not participating in the study, with results indicating that the questions were acceptable and comprehensible.

\section{Analyses}

All analyses were a priori stratified by gender. Missing values were excluded from analyses and all percentages are percentages of valid answers. For analyses pertaining to condom use, participants who reported never having had sex were excluded. 
Sexual risk behaviours were treated as outcome measures. Depression, psychological distress, and alcohol use were examined as possible predictors. However, depression, psychological distress, and alcohol use may all be inter-related. For instance, alcohol use may be both a consequence and a cause of psychological distress and depression. Thus, each of these measures was examined separately in relationship to sexual risk behaviour. Socio-demographic background factors were included into all models in order to adjust for confounding.

Moreover, in explorative analyses we investigated whether the inter-relatedness between depression, psychological distress and alcohol use influenced their respective associations with the outcome. Thus, we examined whether the associations of depression and psychological distress with sexual risk behaviours were independent of alcohol use, and conversely, whether the association of alcohol use with sexual risk behaviours was independent of depression and psychological distress, respectively. The results of these explorative analyses are presented in the text, but not in the tables.

We used a modified cluster sampling method, with the clusters being villages/neighbourhoods, as contrasted to a genuinely random sampling method. Thus, given that some statistical efficiency may be lost in case responses within clusters correlate, we investigated whether adjustment for such intra-cluster correlation substantially influenced the results obtained, using the Stata svy procedure. However, confidence intervals remained virtually unchanged after adjustment and the original confidence intervals are presented in this manuscript. Significance level was set at $p<0.05$.

\section{Results}

$88 \%$ of the men and $82 \%$ of the women reported ever having had sex. $37 \%(n=123)$ of the men and $23 \%(n=$ 70) of the women reported four or more lifetime sexual partners. $15 \%(n=49)$ of the men and $4.5 \%(n=14)$ of the women reported having concurrent sexual partners. $73 \%(n=204)$ of the men and $77 \%(n=193)$ of the women who had ever had sex reported inconsistent condom use.

The prevalence of probable depression was $12.0 \%$ among men and $17.9 \%$ among women. Heavy episodic drinking at least once per week was reported by $35.4 \%$ $(n=118)$ of the men and $13.3 \%(n=41)$ of the women. The distribution of socio-demographic, mental health and sexual risk behaviour variables are presented in Table 1.

\section{Depression and sexual risk behaviours}

Depression was independently associated with a greater number of lifetime sexual partners among women, but
Table 1 Sample characteristics

\begin{tabular}{|c|c|c|}
\hline Characteristic & $\begin{array}{l}\text { Men, } n=334 \\
\mathrm{n}(\%)\end{array}$ & $\begin{array}{l}\text { Women, } \mathrm{n}=312 \\
\mathrm{n}(\%)\end{array}$ \\
\hline \multicolumn{3}{|l|}{ Age } \\
\hline $18-24$ yrs & $161(48.2)$ & $176(56.4)$ \\
\hline $25-30$ yrs & $173(51.8)$ & $136(43.6)$ \\
\hline \multicolumn{3}{|l|}{ Education } \\
\hline$<=7$ yrs & $110(33.1)$ & $97(31.3)$ \\
\hline$>7$ yrs & $222(66.9)$ & $213(68.7)$ \\
\hline \multicolumn{3}{|l|}{ Place of residence } \\
\hline Urban & $115(34.4)$ & $102(32.7)$ \\
\hline Semiurban/rural & $219(65.6)$ & $210(67.3)$ \\
\hline \multicolumn{3}{|l|}{ Relationship status } \\
\hline Single/widowed/separated & $178(53.6)$ & $179(57.6)$ \\
\hline Married/cohabiting & $154(46.4)$ & $132(42.4)$ \\
\hline \multicolumn{3}{|l|}{ Depression } \\
\hline No & $294(88.0)$ & $256(82.1)$ \\
\hline Yes & $40(12.0)$ & $56(17.9)$ \\
\hline \multicolumn{3}{|l|}{ Psychological distress $^{1}$} \\
\hline Lower quartile & 1.16 & 1.16 \\
\hline Median & 1.28 & 1.36 \\
\hline Upper quartile & 1.64 & 1.80 \\
\hline \multicolumn{3}{|l|}{ Alcohol use $^{2}$} \\
\hline Less than once per week & $215(64.6)$ & $268(86.7)$ \\
\hline At least once per week & $118(35.4)$ & $41(13.3)$ \\
\hline \multicolumn{3}{|l|}{ Lifetime sexual partners } \\
\hline 0 & $41(12.4)$ & $56(18.0)$ \\
\hline 1 & $69(20.9)$ & 89 (28.6) \\
\hline 2 & $56(17.0)$ & $60(19.3)$ \\
\hline 3 & $41(12.4)$ & $36(11.6)$ \\
\hline 4 or above & $123(37.3)$ & $70(22.5)$ \\
\hline \multicolumn{3}{|l|}{ Current sexual partners } \\
\hline 0 & $98(29.8)$ & $93(30.0)$ \\
\hline 1 & $182(55.3)$ & $203(65.5)$ \\
\hline 2 & $42(12.8)$ & $12(3.9)$ \\
\hline 3 & $4(1.2)$ & $2(0.6)$ \\
\hline 4 & $3(0.9)$ & $0(0)$ \\
\hline \multicolumn{3}{|l|}{${\text { Condom } \text { use }^{3}(n=544)}$} \\
\hline Always & $77(27.4)$ & $57(22.8)$ \\
\hline Sometimes & $110(39.1)$ & $109(43.6)$ \\
\hline Never & $94(33.5)$ & $84(33.6)$ \\
\hline
\end{tabular}

${ }^{1}$ Values represent HSCL-25 quartiles cut-off scores.

${ }^{2}$ Alcohol use refers to self-reported heavy episodic drinking.

${ }^{3}$ Condom use was assessed only among those participants who had ever had sex

not among men, after simultaneous adjustment for all socio-demographic background variables, see Table 2 . Similarly, depression was independently associated with having concurrent sexual partners among women, but not among men. Associations between depression and inconsistent condom use did not reach statistical significance in either men or women. 
Table 2 Association of depression with sexual risk behaviours in 334 men and 312 women aged 18-30 years in the general population in Uganda

\begin{tabular}{|c|c|c|c|c|c|c|c|c|c|}
\hline \multirow[b]{2}{*}{ Depression } & \multicolumn{3}{|c|}{ Lifetime partners } & \multicolumn{3}{|c|}{ Current regular partners } & \multicolumn{3}{|c|}{ Inconsistent condom use ${ }^{2}$} \\
\hline & $\begin{array}{l}\text { Proportion } \\
\text { with } \\
4 \text { or more } \\
\text { lifetime } \\
\text { partners } \\
(\%)\end{array}$ & $\begin{array}{c}\text { Crude } \\
\text { OR } \\
(95 \% \mathrm{Cl})\end{array}$ & $\begin{array}{c}\text { Adjusted }^{1} \\
\text { OR } \\
(95 \% \mathrm{Cl})\end{array}$ & $\begin{array}{l}\text { Proportion } \\
\text { with } \\
\text { more than } 1 \\
\text { current } \\
\text { partner } \\
(\%)\end{array}$ & $\begin{array}{c}\text { Crude } \\
\text { OR } \\
(95 \% \mathrm{Cl})\end{array}$ & $\begin{array}{c}\text { Adjusted }^{1} \\
\text { OR } \\
(95 \% \mathrm{Cl})\end{array}$ & $\begin{array}{l}\text { Proportion } \\
\text { with } \\
\text { inconsistent } \\
\text { condom use } \\
(\%)\end{array}$ & $\begin{array}{c}\text { Crude } \\
\text { OR } \\
(95 \% \mathrm{Cl})\end{array}$ & $\begin{array}{c}\text { Adjusted }^{1} \\
\text { OR } \\
(95 \% \mathrm{Cl})\end{array}$ \\
\hline \multicolumn{10}{|l|}{ Men } \\
\hline $\begin{array}{l}\text { No } \\
\text { depression }\end{array}$ & $\begin{array}{c}104 / 290 \\
(35.9)\end{array}$ & 1 & 1 & $\begin{array}{c}41 / 290 \\
(14.1)\end{array}$ & 1 & 1 & $\begin{array}{c}171 / 243 \\
(70.4)\end{array}$ & 1 & 1 \\
\hline Depression & $\begin{array}{l}19 / 40 \\
(47.5) \\
\end{array}$ & $\begin{array}{c}1.62 \\
(0.83-3.15) \\
\end{array}$ & $\begin{array}{c}1.63 \\
(0.78-3.42) \\
\end{array}$ & $\begin{array}{c}8 / 39 \\
(20.5) \\
\end{array}$ & $\begin{array}{c}1.57 \\
(0.67-3.65) \\
\end{array}$ & $\begin{array}{c}1.52 \\
(0.60-3.86) \\
\end{array}$ & $\begin{array}{r}33 / 38 \\
(86.8) \\
\end{array}$ & $\begin{array}{c}2.78 \\
(1.04-7.41) \\
\end{array}$ & $\begin{array}{c}2.71 \\
(0.72-10.20) \\
\end{array}$ \\
\hline \multicolumn{10}{|l|}{ Women } \\
\hline $\begin{array}{l}\text { No } \\
\text { depression }\end{array}$ & $\begin{array}{r}47 / 255 \\
(18.4)\end{array}$ & 1 & 1 & $\begin{array}{c}8 / 254 \\
(3.1)\end{array}$ & 1 & 1 & $\begin{array}{c}150 / 199 \\
(75.4)\end{array}$ & 1 & 1 \\
\hline Depression & $\begin{array}{l}23 / 56 \\
(41.1)\end{array}$ & $\begin{array}{c}3.08 \\
(1.66-5.73)\end{array}$ & $\begin{array}{c}2.74 \\
(1.41-5.34)\end{array}$ & $\begin{array}{l}6 / 56 \\
(10.7)\end{array}$ & $\begin{array}{c}3.69 \\
(1.23-11.10)\end{array}$ & $\begin{array}{c}3.92 \\
(1.25-12.27)\end{array}$ & $\begin{array}{l}43 / 51 \\
(84.3)\end{array}$ & $\begin{array}{c}1.76 \\
(0.77-3.99)\end{array}$ & $\begin{array}{c}2.12 \\
(0.79-5.68)\end{array}$ \\
\hline
\end{tabular}

${ }^{1}$ Adjustment for age, education, marital status and place of residence.

${ }^{2}$ Analyses pertain only to participants who had ever had sex.

When the above results were adjusted for alcohol use in explorative analyses, the association between depression and concurrent sexual partners in women was somewhat attenuated (OR 3.03; 95\% CI 0.90-10.24), indicating that alcohol use mediated or confounded some part of that association. However, associations of depression with number of lifetime sexual partners and with condom use, respectively, were independent of alcohol use in both men and women.

\section{Psychological distress and sexual risk behaviours}

Psychological distress was independently associated with a greater number of lifetime sexual partners in both men and women, after simultaneous adjustment for socio-demographic background variables, see Table 3. The association between psychological distress and having concurrent sexual partners did not reach statistical significance in either men or women, although in women the association approached significance $(\mathrm{p}=$ 0.05). Psychological distress was associated with inconsistent condom use in men, while in women results did not reach statistical significance.

Explorative adjustment of the above associations for alcohol use suggested that the associations between psychological distress and sexual risk behaviours were virtually independent of alcohol use in both men and women.

\section{Alcohol use and sexual risk behaviours}

Alcohol use was independently associated with a greater number of lifetime sexual partners in both men and women, after simultaneous adjustment for socio-demographic variables, see Table 4. Moreover, alcohol use was independently associated with having concurrent sexual partners in both men and women. Associations between alcohol use and inconsistent condom use did not reach statistical significance in either men or women.

When the above associations were adjusted for depression and psychological distress, respectively, the associations between alcohol use and sexual risk behaviours remained virtually unchanged in both men and women.

\section{Discussion}

\section{Main findings}

Depression, psychological distress and alcohol use were all associated with having a greater number of lifetime sexual partners and with having concurrent sexual partners, with stronger associations found among women. Moreover, although less consistent, associations were found between mental health indicators and inconsistent condom use, with stronger associations found among men.

All the above associations were adjusted for confounding by socio-demographic variables. Explorative analyses suggested that the associations of depression and psychological distress with sexual risk behaviours were virtually independent of alcohol use. Conversely, the association between alcohol use and sexual risk behaviours was virtually independent of depression and psychological distress.

The prevalence of depression was in line with earlier Ugandan studies $[23,24]$ but lower than the extremely high prevalence recently reported in war-torn Northern Uganda [25,26]. Heavy episodic drinking at least once per week was common, consistent with reports suggesting 
Table 3 Association of psychological distress with sexual risk behaviours in 334 men and 312 women aged 18-30 years in the general population in Uganda

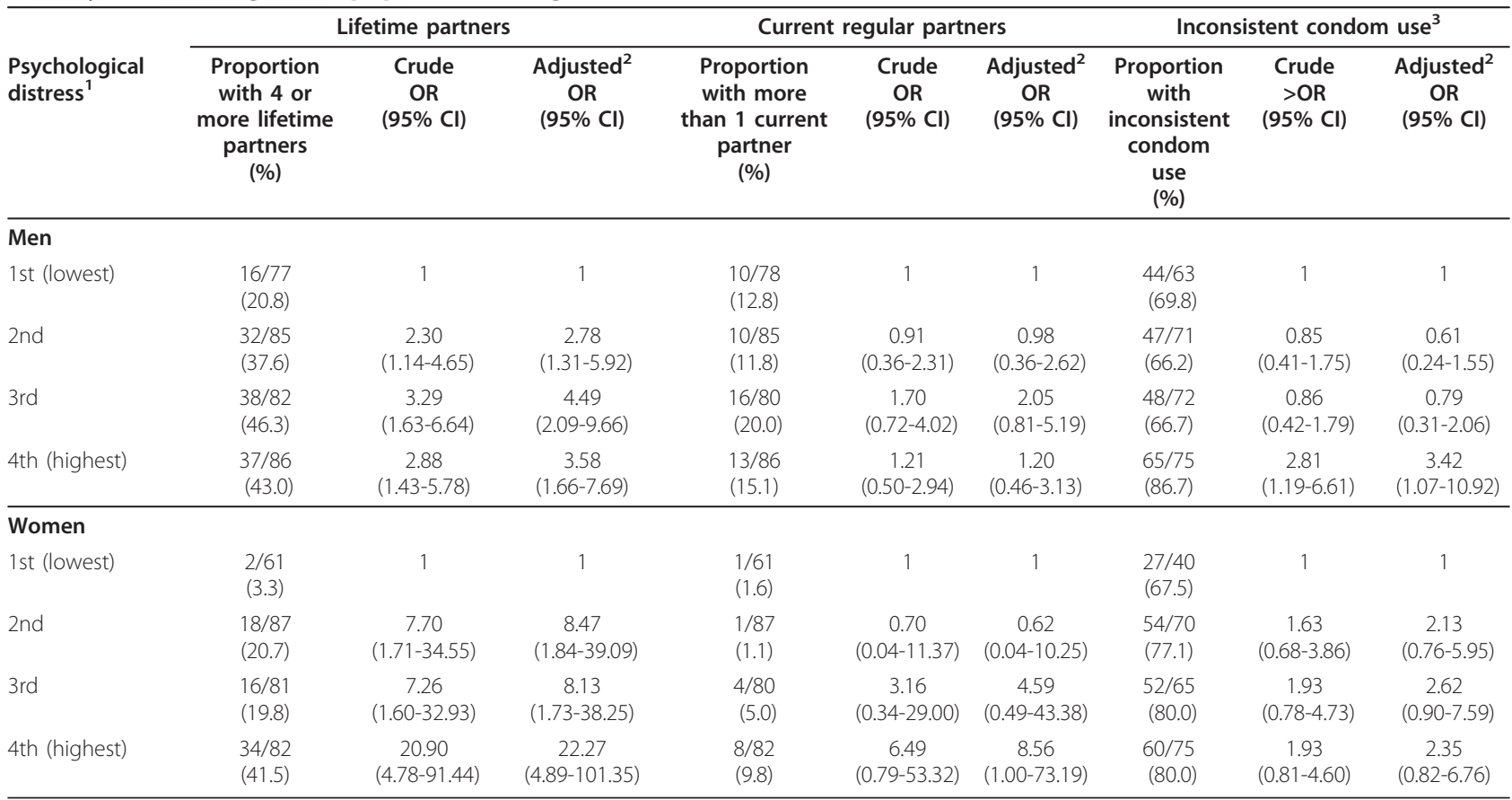

${ }^{1}$ Numbers represent HSCL-25 quartiles.

${ }^{2}$ Adjustment for age, education, marital status and place of residence.

${ }^{3}$ Analyses pertain only to participants who had ever had sex.

that Uganda has one of the world's highest alcohol per capita consumptions [38]. The mean number of lifetime partners among persons who had ever had sex was broadly in the same range as that reported in a national survey conducted at the time of this study [22]. The point prevalence of concurrency was relatively low, although consistent with previous Ugandan studies on concurrency $[39,40]$. Inconsistent condom use was reported by approximately $75 \%$ of those who had ever had sex, in agreement with reports of low rates of condom use at last sexual intercourse from the period when this study was performed [22].

Table 4 Association of alcohol use with sexual risk behaviours in 334 men and 312 women aged 18-30 years in the general population in Uganda

\begin{tabular}{|c|c|c|c|c|c|c|c|c|c|}
\hline \multirow[b]{2}{*}{ Alcohol use } & \multicolumn{3}{|c|}{ Lifetime partners } & \multicolumn{3}{|c|}{ Current regular partners } & \multicolumn{3}{|c|}{ Inconsistent condom use ${ }^{2}$} \\
\hline & $\begin{array}{c}\text { Proportion } \\
\text { with } 4 \\
\text { or more } \\
\text { lifetime } \\
\text { partners } \\
(\%)\end{array}$ & $\begin{array}{c}\text { Crude } \\
\text { OR } \\
(95 \% \mathrm{Cl})\end{array}$ & $\begin{array}{c}\text { Adjusted }^{1} \\
\text { OR } \\
(95 \% \mathrm{Cl})\end{array}$ & $\begin{array}{l}\text { Proportion } \\
\text { with } \\
\text { more than } 1 \\
\text { current } \\
\text { partner } \\
\text { (\%) }\end{array}$ & $\begin{array}{c}\text { Crude } \\
\text { OR } \\
(95 \% \mathrm{Cl})\end{array}$ & $\begin{array}{c}\text { Adjusted }^{1} \\
\text { OR } \\
(95 \% \mathrm{Cl})\end{array}$ & $\begin{array}{l}\text { Proportion } \\
\text { with } \\
\text { inconsistent } \\
\text { condom use } \\
(\%)\end{array}$ & $\begin{array}{c}\text { Crude } \\
\text { OR } \\
(95 \% \mathrm{Cl})\end{array}$ & $\begin{array}{c}\text { Adjusted }^{1} \\
\text { OR } \\
(95 \% \mathrm{Cl})\end{array}$ \\
\hline \multicolumn{10}{|l|}{ Men } \\
\hline $\begin{array}{l}\text { Less than once per } \\
\text { week }\end{array}$ & $\begin{array}{c}64 / 213 \\
(30.0)\end{array}$ & 1 & 1 & $\begin{array}{c}20 / 211 \\
(9.5)\end{array}$ & 1 & 1 & $\begin{array}{c}108 / 166 \\
(65.1)\end{array}$ & 1 & 1 \\
\hline $\begin{array}{l}\text { At least once per } \\
\text { week }\end{array}$ & $\begin{array}{c}59 / 116 \\
(50.9)\end{array}$ & $\begin{array}{c}2.41 \\
(1.51-3.85)\end{array}$ & $\begin{array}{c}1.82 \\
(1.09-3.03)\end{array}$ & $\begin{array}{r}29 / 117 \\
(24.8)\end{array}$ & $\begin{array}{c}3.15 \\
(1.69-5.87)\end{array}$ & $\begin{array}{c}2.11 \\
(1.08-4.11)\end{array}$ & $\begin{array}{c}95 / 114 \\
(83.3)\end{array}$ & $\begin{array}{c}2.69 \\
(1.49-4.83)\end{array}$ & $\begin{array}{c}1.70 \\
(0.83-3.48)\end{array}$ \\
\hline \multicolumn{10}{|l|}{ Women } \\
\hline $\begin{array}{l}\text { Less than once per } \\
\text { week }\end{array}$ & $\begin{array}{c}45 / 268 \\
(16.8)\end{array}$ & 1 & 1 & $\begin{array}{c}6 / 268 \\
(2.2)\end{array}$ & 1 & 1 & $\begin{array}{c}159 / 208 \\
(76.4)\end{array}$ & 1 & 1 \\
\hline $\begin{array}{l}\text { At least once per } \\
\text { week }\end{array}$ & $\begin{array}{c}25 / 41 \\
(61.0)\end{array}$ & $\begin{array}{c}7.74 \\
(3.83-15.66)\end{array}$ & $\begin{array}{c}7.75 \\
(3.63-16.57)\end{array}$ & $\begin{array}{c}8 / 41 \\
(19.5)\end{array}$ & $\begin{array}{c}10.59 \\
(3.46-32.40)\end{array}$ & $\begin{array}{c}11.88 \\
(3.66-38.53)\end{array}$ & $\begin{array}{l}34 / 40 \\
(85.0)\end{array}$ & $\begin{array}{c}1.75 \\
(0.69-4.40)\end{array}$ & $\begin{array}{c}1.99 \\
(0.68-5.79)\end{array}$ \\
\hline
\end{tabular}

${ }^{1}$ Adjustment for age, education, marital status and place of residence.

${ }^{2}$ Analyses pertain only to participants who had ever had sex. 


\section{Interpretation}

Depression was associated with past and current multiple partners in women. A number of interpretations for these associations are possible. Firstly, depression and multiple partners may be indirectly linked through a common cause. For instance, poverty with food insecurity may cause poor mental health, and may also force women into transactional sexual relationships in order to obtain food [41]. Similarly, having an abusive partner may lead to depression, while also motivating women to look for extramarital or alternative partners. Secondly, depression might contribute to having multiple partners. Thus, fatalism and hopelessness may lead to disregard of the threat of HIV and thus hypothetically contribute to multiple sexual partnerships [42]. Moreover, depressed women may be more vulnerable to being coerced into sex, potentially leading to an increased number of sexual contacts [20]. Thirdly, having multiple partners might lead to depression. Thus, having multiple partners may cause HIV related worries [43]. Moreover, STD and HIV infection increase the risk of subsequent depression $[4,10]$. In addition, women with multiple partners in Uganda may have feelings of guilt and may fear being labelled as promiscuous [44]. More research is needed in order to clarify the meaning of the association between depression and multiple partners in the Ugandan context.

Similarly, the associations between psychological distress and past and current partners were stronger in women. Studies in high-income countries suggest that women having multiple partners may have particularly poor mental health $[11,12]$. Psychological distress and depression partly overlap, and factors contributing to multiple partners in depressed women could also be operating with regard to psychological distress. In addition, psychological distress may lead to casual sex as a coping strategy, and may also decrease self-efficacy for changing risky habits [45]. Lack of sense of the future may lead to non-planning and impulsivity [46]. In addition, psychological distress may cause destructiveness [29], potentially contributing to sexual risk behaviours.

In contrast, the associations of depression and psychological distress with inconsistent condom use were stronger among men. Men's mental state may have a greater influence than that of women on the condomuse decision, given that men generally decide over condom use in Uganda [47].

While associations between alcohol use and sexual risk behaviours have previously been found in Uganda [48], the mechanisms explaining the association between alcohol use and sexual risk behaviours in this setting, or elsewhere, are not fully understood: Clearly, alcohol consumption causes behavioural disinhibition potentially leading to risky decisions. However, alcohol use may also be a marker for a psychological trait, or state, conducive to risky sexual behaviours $[49,50]$, e.g. depression or psychological distress. In the context of this uncertainty, the current findings, although cross-sectional, do suggest that alcohol use and depression/psychological distress mainly influence sexual risk behaviours through mutually independent causal pathways.

In summary, the interrelationship between poor mental health and sexual risk behaviours in the Ugandan setting is likely complex, and may well be bi-directional.

\section{Methodological considerations}

The current study was cross-sectional and its aim was to assess association. Thus, the interpretations presented regarding the possible nature and direction of the associations should be viewed as hypotheses for further testing.

Our measure of concurrency was crude, although standard definitions of concurrency are still under development [51]. The measure involved some portion of subjectivity given that what is perceived as a current regular sexual partner depends on expectations of future encounters. However, 'current' regular relationships have been assessed also in previous studies $[35,39,40]$. Moreover, the measure was not subject to recall bias since participants were not required to reconstruct past partnerships. In addition, recall and concentration is affected by depressive symptoms [52] and an assessment of dates and frequencies of sexual behaviours in the past would potentially have entailed significant risks of bias.

As in much survey research on sensitive topics, responses may be subject to social desirability bias. Having multiple sexual partners is often not socially desirable for women in Uganda, and the numbers of partners and rates of concurrency reported among women should be viewed as minimum estimates. However, the rates found are largely consistent with evidence from previous studies on concurrency from Uganda $[39,40]$.

The sampling method used was not random, since villages/neighbourhoods were purposively selected. Thus, the socio-demographic profile of the sample does not necessarily reflect that of the districts where the study was performed. In the current sample, the proportion of persons having completed primary school was higher and the proportion of persons who were married or cohabiting was lower than in the general population in Uganda [53], although it should be noted that only persons aged 18-30 years were included in the study. While the prevalence estimates should thus be interpreted with some caution, the purposive sampling of villages/neighbourhoods representing a broad range of economic development arguably increases the extent to which the associations found may be applicable to external populations from different socio-economic strata. 
Follow-up visits were not performed for households where no one was at home at the time of the interviewer's visit. If persons who were not at home systematically differed from those at home with respect to mental health and sexual risk behaviours, a selection bias could hypothetically have been introduced into the study.

No measure of personal or household wealth was included. However, results were adjusted for a proxy measure of socio-economic status (i.e. education) and place of residence.

The alcohol measure was crude and did not capture nuances in alcohol consumption, such as the exact number of drinks per heavy episodic drinking occasion. However, when investigating the behavioural impact of heavy episodic drinking, solely assessing the number of standard drinks may have limitations, given that the number of drinks required for altering behaviour is individual [54]. Thus, combining self-reports of heavy episodic drinking with standard drink counts may provide the best option for research on alcohol and sexual risk behaviours, particularly in settings where the 'standard drink' concept is difficult to operationalise.

\section{Conclusions}

To our knowledge, this is the first population-based study to demonstrate an association of depression and psychological distress with sexual risk behaviours in a low-income sub-Saharan African setting. Although preliminary, the current findings indicate that the association between poor mental health and sexual risk behaviours may be present across both high and low-income settings, despite radical contextual differences e.g. in terms of economic wealth, gender inequality, level of urbanisation, personal mobility and religious norms, i.e. structural factors of relevance for sexual risk behaviours $[14,18]$.

Indeed, the current findings are consistent with the notion that depression, psychological distress and alcohol use are risk factors for sexual risk behaviours also in sub-Saharan African low-income settings, although longitudinal studies are needed in order to confirm this. Depression, psychological distress and alcohol use are prevalent in many countries with generalised HIV epidemics $[6,23-26,55,56]$. Thus, assuming causality, these conditions could potentially have considerable impact on population rates of sexual risk behaviours in lowincome countries with high HIV prevalence.

Improving mental health may theoretically decrease sexual risk behaviours. Based on our findings and the evidence from high and middle-income countries [9-12,19-21,45] we support the call for mental health intervention trials to include sexual risk behaviour and biological variables as outcome measures [2], particularly in low-income settings with generalised HIV epidemics. Moreover, qualitative studies should further explore subjective experiences of how poor mental health and sexual risk behaviours are inter-connected in lowincome settings [57].

Irrespective of the direction of causality, the mere co-existence of poor mental health and sexual risk behaviours has implications for HIV prevention: Those with the greatest HIV prevention needs may not always be sufficiently psychologically fit to benefit from intervention messages. For instance, learning to be assertive when communicating about sex with one's partner may be difficult for a woman who is depressed and anxious. HIV intervention trials should assess to what extent participants' mental health at baseline influence intervention outcomes. Moreover, HIV preventive programmes may need to consider including mental health and alcohol use reduction components into their intervention packages, in settings and groups where depression, psychological distress and alcohol use are common.

\section{Acknowledgements}

The authors are grateful to all participants in the study. The authors thank Gaetano Marrone for statistical advice. The study was supported by the Swedish International Development Cooperation Agency (SIDA/SAREC) and Lund University.

\section{Author details}

'Division of Social Medicine, Department of Public Health Sciences, Karolinska Institute, Stockholm, Sweden. ${ }^{2}$ Division of Social Medicine and Global Health, Department of Clinical Sciences, Lund University, Malmö, Sweden. ${ }^{3}$ Department of Psychiatry, Mbarara University of Science and Technology, Mbarara, Uganda. ${ }^{4}$ Division of Global Health (IHCAR), Department of Public Health Sciences, Karolinska Institute, Stockholm, Sweden.

\section{Authors' contributions}

PL designed and coordinated the study, performed analyses and wrote the manuscript. GR and SA led the data collection. AT and PA contributed to data analysis and results interpretation. PO contributed to study design, data analysis and results interpretation. EC conceived of the study and contributed to all stages of the work. All authors read and approved the final manuscript.

\section{Competing interests}

The authors declare that they have no competing interests.

Received: 2 November 2010 Accepted: 21 February 2011

Published: 21 February 2011

\section{References}

1. Collins PY, Holman AR, Freeman MC, Patel V: What is the relevance of mental health to HIV/AIDS care and treatment programs in developing countries? A systematic review. AIDS 2006, 20(12):1571-1582.

2. Sikkema KJ, Watt MH, Drabkin AS, Meade CS, Hansen NB, Pence BW: Mental health treatment to reduce HIV transmission risk behavior: a positive prevention model. AIDS Behav 2010, 14(2):252-262.

3. Patel V: Mental health in low- and middle-income countries. Br Med Bull 2007, 81-82:81-96.

4. Ciesla JA, Roberts JE: Meta-analysis of the relationship between HIV infection and risk for depressive disorders. Am J Psychiatry 2001, 158(5):725-730. 
5. Kaharuza FM, Bunnell R, Moss S, Purcell DW, Bikaako-Kajura W, Wamai N Downing R, Solberg P, Coutinho A, Mermin J: Depression and CD4 cell count among persons with HIV infection in Uganda. AIDS Behav 2006, 10(4 Suppl):S105-111.

6. Chipimo PJ, Fylkesnes K: Mental distress in the general population in Zambia: impact of HIV and social factors. BMC Public Health 2009, 9:298.

7. Myer L, Seedat S, Stein DJ, Moomal H, Williams DR: The mental health impact of AIDS-related mortality in South Africa: a national study. $J$ Epidemiol Community Health 2009, 63(4):293-298.

8. Bolton P, C MW: How do Africans view the impact of HIV? A report from a Ugandan community. AIDS Care 2004, 16(1):123-128.

9. Ramrakha S, Caspi A, Dickson N, Moffitt TE, Paul C: Psychiatric disorders and risky sexual behaviour in young adulthood: cross sectional study in birth cohort. BMJ 2000, 321(7256):263-266.

10. Shrier LA, Harris SK, Beardslee WR: Temporal associations between depressive symptoms and self-reported sexually transmitted disease among adolescents. Arch Pediatr Adolesc Med 2002, 156(6):599-606.

11. Lehrer JA, Shrier LA, Gortmaker S, Buka S: Depressive symptoms as a longitudinal predictor of sexual risk behaviors among US middle and high school students. Pediatrics 2006, 118(1):189-200.

12. DiClemente RJ, Wingood GM, Crosby RA, Sionean C, Brown LK, Rothbaum B, Zimand E, Cobb BK, Harrington K, Davies S: A prospective study of psychological distress and sexual risk behavior among black adolescent females. Pediatrics 2001, 108(5):E85.

13. Reisner SL, Mimiaga MJ, Skeer M, Bright D, Cranston K, Isenberg D, Bland S, Barker TA, Mayer KH: Clinically significant depressive symptoms as a risk factor for HIV infection among black MSM in Massachusetts. AIDS Behav 2009, 13(4):798-810.

14. Wellings K, Collumbien M, Slaymaker E, Singh S, Hodges Z, Patel D, Bajos N: Sexual behaviour in context: a global perspective. Lancet 2006, 368(9548):1706-1728.

15. Gillespie S, Kadiyala S, Greener R: Is poverty or wealth driving HIV transmission? AIDS 2007, 21(Suppl 7):S5-S16.

16. Barnighausen T, Hosegood V, Timaeus IM, Newell ML: The socioeconomic determinants of HIV incidence: evidence from a longitudinal, populationbased study in rural South Africa. AIDS 2007, 21(Suppl 7):S29-38.

17. Jewkes R, Dunkle K, Nduna M, Levin J, Jama N, Khuzwayo N, Koss M, Puren A, Duvvury N: Factors associated with HIV sero-status in young rural South African women: connections between intimate partner violence and HIV. Int J Epidemiol 2006, 35(6):1461-1468.

18. Gupta GR, Parkhurst JO, Ogden JA, Aggleton P, Mahal A: Structural approaches to HIV prevention. Lancet 2008, 372(9640):764-775.

19. Nduna M, Jewkes RK, Dunkle KL, Shai NP, Colman I: Associations between depressive symptoms, sexual behaviour and relationship characteristics: a prospective cohort study of young women and men in the Eastern Cape, South Africa. J Int AIDS Soc 2010, 13:44.

20. Smit J, Myer L, Middelkoop K, Seedat S, Wood R, Bekker LG, Stein DJ: Mental health and sexual risk behaviours in a South African township: a community-based cross-sectional study. Public Health 2006, 120(6):534-542.

21. Weiser SD, Leiter K, Heisler M, McFarland W, Percy-de Korte F, DeMonner SM, Tlou S, Phaladze N, lacopino V, Bangsberg DR: A population-based study on alcohol and high-risk sexual behaviors in Botswana. PLoS Med 2006, 3(10):e392.

22. MOH: Uganda HIV/AIDS Sero-behavioural Survey 2004-2005 Calverton, Maryland, USA: Ministry of Health and ORC Macro; 2006.

23. Ovuga E, Boardman J, Wasserman D: The prevalence of depression in two districts of Uganda. Soc Psychiatry Psychiatr Epidemiol 2005, 40(6):439-445

24. Bolton P, Wilk CM, Ndogoni L: Assessment of depression prevalence in rural Uganda using symptom and function criteria. Soc Psychiatry Psychiatr Epidemiol 2004, 39(6):442-447.

25. Vinck P, Pham PN, Stover E, Weinstein HM: Exposure to war crimes and implications for peace building in northern Uganda. JAMA 2007, 298(5):543-554.

26. Kinyanda E, Woodburn P, Tugumisirize J, Kagugube J, Ndyanabangi S, Patel V: Poverty, life events and the risk for depression in Uganda. Soc Psychiatry Psychiatr Epidemiol 2011, 46(1):35-44.

27. Kigozi F, Ssebunnya J, Kizza D, Cooper S, Ndyanabangi S: An overview of Uganda's mental health care system: results from an assessment using the world health organization's assessment instrument for mental health systems (WHO-AIMS). Int J Ment Health Syst 2010, 4(1):1.
28. Derogatis LR, Lipman RS, Rickels K, Uhlenhuth EH, Covi L: The Hopkins Symptom Checklist (HSCL): a self-report symptom inventory. Behav Sci 1974, 19(1):1-15

29. Cross-cultural assessment of trauma-related mental illness (Phase II). World Vision Uganda and the Johns Hopkins University; 2001 [http://www. certi.org/publications/policy/ugandafinahreport.htm].

30. Kagee A: Psychological distress among persons living with HIV hypertension, and diabetes. AIDS Care 2010, 1-5.

31. Bakken K, Landheim AS, Vaglum P: Axis I and II disorders as long-term predictors of mental distress: a six-year prospective follow-up of substance-dependent patients. BMC Psychiatry 2007, 7:29.

32. Chersich MF, Luchters SM, Malonza IM, Mwarogo P, King'ola N, Temmerman M: Heavy episodic drinking among Kenyan female sex workers is associated with unsafe sex, sexual violence and sexually transmitted infections. Int J STD AIDS 2007, 18(11):764-769.

33. Kalichman SC, Simbayi LC, Kaufman M, Cain D, Jooste S: Alcohol use and sexual risks for HIV/AIDS in sub-Saharan Africa: systematic review of empirical findings. Prev Sci 2007, 8(2):141-151

34. Kabiru CW, Beguy D, Crichton J, Ezeh AC: Self-reported drunkenness among adolescents in four sub-Saharan African countries: associations with adverse childhood experiences. Child Adolesc Psychiatry Ment Health 2010, 4:17.

35. Harrison A, Cleland J, Frohlich J: Young people's sexual partnerships in KwaZulu-Natal, South Africa: patterns, contextual influences, and HIV risk. Stud Fam Plann 2008, 39(4):295-308.

36. Mah TL, Halperin DT: Concurrent sexual partnerships and the HIV epidemics in Africa: evidence to move forward. AIDS Behav 2010, 14(1):11-16, dicussion 34-17.

37. Schroder KE, Carey MP, Vanable PA: Methodological challenges in research on sexual risk behavior: I. Item content, scaling, and data analytical options. Ann Behav Med 2003, 26(2):76-103.

38. WHO: Global Status Report on Alcohol 2004 Geneva: WHO; 2004

39. Carael M, Ali M, Cleland J: Nuptionality and risk behaviour in Lusaka and Kampala. African Journal of Reproductive Health 2001, 5:83-89.

40. Morris M, Kretzschmar M: A microsimulation study of the effect of concurrent partnerships on the spread of HIV in Uganda. Mathematical Population Studies 2000, 8(2):109-133.

41. Weiser SD, Leiter K, Bangsberg DR, Butler LM, Percy-de Korte F, Hlanze Z, Phaladze N, lacopino V, Heisler M: Food insufficiency is associated with high-risk sexual behavior among women in Botswana and Swaziland. PLoS Med 2007, 4(10):1589-1597, discussion 1598.

42. Kalichman SC, Kelly JA, Morgan M, Rompa D: Fatalism, current life satisfaction, and risk for HIV infection among gay and bisexual men. J Consult Clin Psychol 1997, 65(4):542-546.

43. Myer L, Stein DJ, Grimsrud AT, Herman A, Seedat S, Moomal H, Williams DR: DSM-IV-defined common mental disorders: association with HIV testing, HIV-related fears, perceived risk and preventive behaviours among South African adults. S Afr Med J 2009, 99(5 Pt 2):396-402.

44. McGrath JW, Rwabukwali CB, Schumann DA, Pearson-Marks J, Nakayiwa S, Namande B, Nakyobe L, Mukasa R: Anthropology and AIDS: the cultural context of sexual risk behavior among urban Baganda women in Kampala, Uganda. Soc Sci Med 1993, 36(4):429-439.

45. Seth P, Raiji PT, DiClemente RJ, Wingood GM, Rose E: Psychological distress as a correlate of a biologically confirmed STI, risky sexual practices, self-efficacy and communication with male sex partners in African-American female adolescents. Psychol Health Med 2009, 14(3):291-300.

46. Swann AC, Steinberg UL, Lijfijt M, Moeller FG: Impulsivity: differential relationship to depression and mania in bipolar disorder. $J$ Affect Disord 2008, 106(3):241-248

47. Blanc AK, Wolff B: Gender and decision-making over condom use in two districts in Uganda. Afr J Reprod Health 2001, 5(3):15-28.

48. Zablotska IB, Gray RH, Serwadda D, Nalugoda F, Kigozi G, Sewankambo N, Lutalo T, Mangen FW, Wawer M: Alcohol use before sex and HIV acquisition: a longitudinal study in Rakai, Uganda. AIDS 2006, 20(8):1191-1196.

49. Wolff B, Busza J, Bufumbo L, Whitworth J: Women who fall by the roadside: gender, sexual risk and alcohol in rural Uganda. Addiction 2006, 101(9):1277-1284.

50. Weinhardt LS, Carey MP: Does alcohol lead to sexual risk behavior? Findings from event-level research. Annu Rev Sex Res 2000, 11:125-157. 
51. UNAIDS Reference Group on Estimates M, and Projections: Working Group on Measuring Concurrent Sexual Partnerships: HIV: consensus indicators are needed for concurrency. Lancet 2010, 375(9715):621-622.

52. Gotlib $\mid \mathrm{H}$, Joormann J: Cognition and depression: current status and future directions. Annu Rev Clin Psychol 2010, 6:285-312.

53. UBOS: Uganda Demographic and Health Survey Calverton: UBOS and Macro International Inc; 2006

54. Midanik LT: Definitions of drunkenness. Subst Use Misuse 2003, 38(9):1285-1303.

55. Tomlinson M, Grimsrud AT, Stein DJ, Williams DR, Myer L: The epidemiology of major depression in South Africa: results from the South African stress and health study. S Afr Med J 2009, 99(5 Pt 2):367-373.

56. Fritz K, Morojele N, Kalichman S: Alcohol: the forgotten drug in HIV/AIDS. Lancet 2010, 376(9739):398-400.

57. Wright J, Lubben F, Mkandawire MB: Young Malawians on the interaction between mental health and HIV/AIDS. African Journal of AIDS Research 2007, 6(3):297-304

\section{Pre-publication history}

The pre-publication history for this paper can be accessed here: http://www.biomedcentral.com/1471-2458/11/125/prepub

doi:10.1186/1471-2458-11-125

Cite this article as: Lundberg et al:: Poor mental health and sexual risk behaviours in Uganda: A cross-sectional population-based study. BMC Public Health 2011 11:125.

\section{Submit your next manuscript to BioMed Central and take full advantage of:}

- Convenient online submission

- Thorough peer review

- No space constraints or color figure charges

- Immediate publication on acceptance

- Inclusion in PubMed, CAS, Scopus and Google Scholar

- Research which is freely available for redistribution

Submit your manuscript at www.biomedcentral.com/submit 